\title{
Kırıkkale Toplum Ruh Sağlığı Merkezi’nde Takip Edilen Şizofreni Hastalarının Değerlendirilmesi
}

\author{
The Evaluation of the Schizophrenia Patiens in Kirikkale Community Mental Health Center
}

\author{
Esen Uz GÜL ${ }^{1}$, Devrim Öztürk CAN ${ }^{1}$, Emine Hande Kılıçaslan ŞAHİN ${ }^{1}$, Şehriban ŞAHİN ${ }^{2}$, \\ Emine ŞİMŞEK ${ }^{3}$, \\ ${ }^{1}$ Kırıkkale Yüksek Ihtisas Hastanesi Psikiyatri Kliniği, KIRIKKALE \\ ${ }^{2}$ Kırlkkale Yüksek İhtisas Hastanesi Psikiyatri Kliniği, KIRIKKALE \\ ${ }^{3}$ Turgut Özal Üniversitesi, Psikiyatri Ana Bilim Dall, ANKARA
}

\begin{abstract}
ÖZET
Kırıkkale Yüksek İhtisas Hastanesi’ne bağlı toplum ruh sağlığı merkezinde en az 6 aydır düzenli takip edilen şizofreni hastalarının sosyodemografik verilerinin ve klinik özelliklerinin incelenmesi amaçlanmıştır.

Toplum ruh sağlığı merkezine en az 6 aydır düzenli gelen hastalar ile görüşülmüş, çalışma hakkında sözel bilgilendirilme yapılarak hasta ve yakınlarından yazılı onam alınmıştır. Hastaların sosyodemografik bilgileri, toplum ruh sağlığı merkezine devam süreleri, hastalık süreleri, kullandıkları tedavi bilgileri kaydedilmiş, hastalara toplum ruh sağlığı merkezine kabullerinde ve 2014 yılı Mart ayı içinde toplam 2 kez kısa psikiyatrik değerlendirme ölçeği uygulanmıştır. Kısa psikiyatrik değerlendirme ölçeği sonuçları istatistiksel olarak bağımlı gruplarda t testi ile değerlendirilmiştir.

Düzenli gelen 28 hasta (11 kadın, 17 erkek) değerlendirilmeye alındı. Erkeklerin yaş ortalaması 39.35 (21-60) iken, kadınların yaş ortalaması 52 (39-61) idi. Hastalığın başlangıç yaşı kadınlarda ortalama 24.27, erkeklerde ortalama 24.17 idi. İlk uygulanan kısa psikiyatrik değerlendirme ölçeği ortalaması 20,9 iken, son kısa psikiyatrik değerlendirme ölçeği ortalaması 16,5 idi. Kısa psikiyatrik değerlendirme ölçeği değerlerindeki düşüş istatistiksel olarak anlamlıydı $(\mathrm{p}<0.001)$. Hastaların hiçbirisinde hastaneye yatışı gerektirecek düzeyde alevlenme olmadı.

Ülkemizde 2009 yılından itibaren toplum ruh sağlı̆̆ merkezleri kurulmaya başlanmıştır. $\mathrm{Bu}$ kapsamda hastalara psikososyal destek hizmetlerinin verilmesi ile hastalığın alevlenme ve yatış oranlarında azalma sağlanabilmektedir. Toplum ruh sağlığı merkezleri ile ilgili çalışmaların artması ve deneyimlerin paylaşılmasının, bu merkezlerin verimliliğini artırabileceğini düşünmekteyiz.

Anahtar Kelimeler: Toplum ruh sağlı̆̆ı merkezi, şizofreni, psikososyal destek
\end{abstract}

\begin{abstract}
It's aimed to evaluate the sociodemographic and clinical features of schizophrenia patients who have been followed up in Kirikkale Yuksek Ihtisas Hospital Community Mental Health Center (CMHC) at least 6 months.

The patients who have been followed up in community mental health center at least 6 monhs were informed about the study and written consents were taken from patients and parents of the patients. Sociodemographic data, the duration of the illness and community mental health center therapy and the medications of the patients were recorded. The brief psychiatric rating scale was also applied to the patients at admission and at the last month of community mental health center therapy. The brief psychiatric rating scale results were evaluated with related groups $t$ test.

Twenty eight patients (male: 17, female:11) were included in the study. The average age of the males was 39.35 years (21-60) and females was 52 years(39-61). The average age of the onset of the disease was 24.27 years in females and 24.17 years in males. The average score of the brief psychiatric rating scale was 20,9 at admission and 16,5 at the last monh of community mental health center therapy. The decrease in scores was statistically significant $(\mathrm{p}<0.001)$. None of the patients required hospitalization during therapy.

Community mental health centers have been established since the year 2009 in Turkey. With the help of these centers the need of hospitalization and exacerbation of the disease may decrease. The increase in the studies and more reliable data about these centers can improve the efficiency of these centers.
\end{abstract}

Keywords: Community mental health center, schizophrenia, psychosocial support
Yazışma Adresi / Correspondence: Esen Uz GÜL

Kırıkkale Yüksek İhtisas Hastanesi Psikiyatri Kliniği, Kırıkkale

E-mail: esenuz@mynet.com Tel: 05054308330 


\section{GíRiş}

Şizofreni, genç yaşta başlayan, insanın kişilerarası ilişkilerden ve gerçeklerden uzaklaşarak kendine özgü bir içe kapanma dünyasında yaşadığı; duygu, düşünce ve davranışlarda önemli bozuklukların görüldüğü ciddi bir ruhsal bozukluktur. (1). Sistematik bir gözden geçirmeye göre Türkiye'de şizofreninin yaşamboyu yaygınlığı genel toplumda 8.9/1000 olarak saptanmıştır (2).

Şizofreni kişinin tüm bilişsel fonksiyonlarını (algılama, dikkat, bellek gibi), duygularını, hareketlerini ve yargılamasını etkileyen bir hastalıktır. Çalışma hayatı, kişilerarası ilişkiler, öz bakım ve yaşam becerileri gibi birçok alanda yetersizliğe yol açabilir. Sahip oldukları yetileri kaybeden, yaşam kalitesi bozulan, çalışmayan hastalar toplumdan da dışlanarak damgalanmaları kolaylaşmaktadır (3).

Antipsikotik ilaçların kullanımıyla hastalık belirtileri önemli ölçüde ortadan kalkmakta, antipsikotik tedavi hastalığın tüm aşamalarında (başlangıç, alevlenme ve koruyucu tedavi) etkili olmaktadır. Ancak, düzenli ilaç kullanımına rağmen iki yıl içinde \%25, 5 yıl içinde ise \%40-60 oranında nüks oluşmaktadır (4). Atakların sayısı arttıkça da hastalığın kronikleşme olasılığı artmakta ve ciddi yeti yitimi meydana gelebilmektedir. Dolayısıyla tedavide hedef yalnızca belirtilerin yatıştırılması değil, hastalığın yıkıcı etkilerinin önlenip, hastanın toplumsal uyumunu arttırmak olmalıdır (5).

$\mathrm{Bu}$ kapsamda şizofreni hastalarının tedavisinde ilaç tedavisine ek olarak verilen ruhsal eğitim, aile eğitimi, sosyal beceri eğitimi, bilişsel davranışçı terapiler gibi ruhsal toplumsal girişimlerin belirtilerin iyileşmesine ve işlevselliğin artmasına yardımcı olduğu saptanmıştır (6). $\mathrm{Bu}$ çalışmada Kırıkkale toplum ruh sağlığı merkezimizde (TRSM) takip edilen hastaların sosyodemografik verilerinin değerlendirilmesi ve merkezimizin etkinliğinin araştırılması amaçlanmıştır.

\section{GEREÇ VE YÖNTEM}

Kırıkkale TRSM'de bireysel görüşmeler, grup terapisi, aile eğitimi, ruhsal-toplumsal beceri eğitiminin yanı sıra; resim, müzik, el-sanatları, oyuncak yapımı, okuma gibi iş-uğraşı aktiviteleri yapılmaktadır. $\mathrm{Bu}$ çalışmaya TRSM ye en az 6 aydır düzenli gelen, 18 yaşından büyük hastalar dahil edilmiştir. Düzenli takibe gelmeyen ya da 6 aydan kısa süredir devam eden hastalar çalışma dışı bırakılmıştır. Çalışma hakkında sözel bilgilendirilme yapılarak hasta ve yakınlarından yazılı onam alınmıştır. Hastalara sosyodemografik bilgi formu ile TRSM ye başladıkları ilk ay ve Mart 2014 içinde olmak üzere 2 kez Kısa Psikiyatrik Değerlendirme ölçeği (KPDÖ) uygulanmıştır. Elde edilen veriler SPSS 15,0 programı kullanılarak analiz edilmiştir. KPDÖ sonuçları istatistiksel olarak bağımlı gruplarda $t$ testi ile değerlendirilmiştir. $\quad \mathrm{p}<0.05$ istatistiksel olarak anlamlı olarak kabul edilmiştir.

\section{Veri toplama araçları}

Sosyodemografik Bilgi Formu: TRSM'de görevli psikiyatri uzmanı tarafından klinik görüşme yapılarak DSM-IV-TR ölçütlerine göre şizofreni tanısı konulmuş olan ve en az 6 aydır TRSM'ye düzenli gelen hastalara uygulanmıştır. Katılımcıların yaş, cinsiyet, eğitim düzeyi, yalnız/birlikte yaşama, TRSM'ye devam süreleri, hastalık süreleri, kullandıkları tedavi bilgilerinden oluşan sosyodemografik veri formu oluşturulmuştur.

\section{Kısa Psikiyatrik Değerlendirme Ölçeği (KPDÖ):}

Kısa bir görüşmeden sonra psikiyatrik belirtilerin ciddiyetini değerlendirmede ya da tedavinin etkilerini değerlendirmede kullanılan, Türkçe geçerlilik güvenilirliği yapılmış, 18 maddelik Likert tipi bir ölçektir (7). Şizofreni ve diğer psikotik bozukluklarda psikotik ve bazı depresif belirtilerin şiddet ve değişimini ölçmekte, tedavinin etkinliğinin değerlendirilmesinde kullanılmaktadır. 


\section{SONUÇLAR}

Toplum ruh sağlığı merkezine düzenli olarak takip edilen 28 şizofreni hastası (11 kadın, 17 erkek) değerlendirilmeye alındı. Erkeklerin yaş ortalaması 39.35 (21-60) iken, kadınların yaş ortalaması 52 (3961) idi. Hastaların 1'i yalnız okuryazar (\% 3.6), 12'si ilkokul (\% 42.9), 5'i ortaokul (\%17.9), 9'u lise (\%32.1) mezunu iken 1'i de yüksekokul (\% 3.6) mezunu idi. Hastaların TRSM ye devam süreleri ortalama $15.35 \pm 6.39$ (6-24) ay civarındaydı. Hastalığın başlangıç yaşı kadınlarda ortalama $24.27 \pm 9.79$ (13-41), erkeklerde ortalama $24.17 \pm 9.25$ (11-43) yaş civarı idi (Tablo1). Antipsikotik kullanımı 10 hastada (\% 35,7) tek ilaç kullanımı şeklinde iken, 18 hasta(\% 64,2) çoklu ilaç kullanmaktaydı. Hastalarımızın 8'i $(\% 28,6)$ depo antipsikotik ile 1 'i $(\%$ 3,6) paliperidon palmitat, 5'i (\%17.8) risperidon, 2'si (\%7.1) zuklopentiksol dekonat) tedavisini sürdürmekteydi. Yalnızca 1 hasta (\%3.5) depo antipsikotiği mono terapi olarak kullanmaktaydı. TRSM' ye kabul edildiklerinde KPDÖ ortalaması 20,9 iken son ay yapılan değerlendirmede KPDÖ ortalaması 16,5 idi. KPDÖ değerlerindeki düşüş istatistiksel olarak anlamlıyd $(\mathrm{p}<0.001)$ (Tablo 2). Hastaların hiçbirinde yatışı gerektirecek düzeyde alevlenme olmadi.

\section{TARTIŞMA}

Ülkemizde 2011 yllından itibaren psikososyal destek hizmetlerinin verilmesi amaciyla TRSM'ler kurulmaya başlanmıştır. Bu kapsamda Kırıkkale ilinde Yüksek İhtisas Hastanesi'ne bağlı olarak kurulan toplum ruh sağlığı merkezimiz 2012 yılında hizmet vermeye başlamıştır. TRSM'leri, hastalara psikososyal destek hizmetlerinin verilmesi, hastaların takip ve tedavilerinin gerektiğinde evde sağlık hizmetleri uygulamasına entegre bir şekilde yaşadıkları ortamda sunulabilmesi, hastaların topluma kazandırılması, yatış oranının azaltılması gibi hedefler doğrultusunda açılmıştır.
Tablo 1. Çalışmaya katılan şizofreni hastalarının sosyodemografik özellikleri

\begin{tabular}{|c|c|c|}
\hline Cinsiyet & $\operatorname{Kadin}(\mathrm{n}=11)$ & Erkek $(\mathrm{n}=17)$ \\
\hline Yaş & $52(39-61)$ & $39.35(21-60)$ \\
\hline Hastalığın & $24.27 \pm 9.79(13-$ & $24.17 \pm 9.25$ \\
\hline Başlama Yaşı & 41) & $(11-43)$ \\
\hline \multirow{3}{*}{$\begin{array}{l}\text { Yalnız/birlikte } \\
\text { yaşama }\end{array}$} & Yalnız yaşıyor & $3(\% 10.7)$ \\
\hline & $\begin{array}{c}\text { Aileyle birlikte } \\
\text { yaşlyor }\end{array}$ & $20(\% 71.4$ \\
\hline & $\begin{array}{c}\text { Bakımevinde } \\
\text { yaşıyor }\end{array}$ & $5(\% 17.9)$ \\
\hline \multirow{5}{*}{ Öğrenim durumu } & Okur-yazar & $1(\% 3.6)$ \\
\hline & İlkokul & $12(\% 42.9)$ \\
\hline & Ortaokul & $5(\% 17.9)$ \\
\hline & Lise & $9(\% 32.1)$ \\
\hline & Yüksekokul & $1(\% 3.6)$ \\
\hline Hastalık süreleri & $20.10 \pm 10.7$ y1l & \\
\hline $\begin{array}{l}\text { TRSM ye devam } \\
\text { süreleri }\end{array}$ & $15.35 \pm 6.4$ ay & \\
\hline
\end{tabular}

Tablo 2. TRSM'de çalışmaya katılan şizofreni hastalarının başlangıç ve son KPDÖ puanları

\begin{tabular}{cc}
\hline KPDÖ (ilk) & KPDÖ (son) \\
$20.9 \pm 8.6(5-40)$ & $16.5 \pm 7.0(5-31)$ \\
\hline $\mathrm{p}<0.001$ &
\end{tabular}

Şizofreni hastalarında uygulanan grup terapilerinin sonuçları incelendiğinde, çalışmaların \%70 inde, terapi gruplarındaki şizofreni hastalarının grup terapisinde olmayan hastalara göre hastalıkla daha iyi baş ettikleri, ilk epizod şizofreni hastalarının da dahil edildiği daha geniş kapsamlı çalışmalarda da psikososyal tedavilerle ilgili (aile psikoeğitim çalışmaları, bilişsel davranışçı terapiler, sosyal beceri çalışmaları) benzer iyileştirici sonuçlara ulaşılmıştır (8). Şizofreni hastalarına altı ay süreyle verilen ruhsal toplumsal beceri eğitiminin etkisinin araştırıldığı bir çalışmada, pozitif ve negatif 
belirtilerle depresif bulguları azalttığı, içgörü ve yaşam kalitesini artırdığı saptanmıştır (9).

Sivas'ta ayaktan 23 şizofreni hastası üzerinde yapılan bir çalışma kapsamında bir psikiyatrist ve bir psikiyatri hemşiresinden oluşan çalışma ekibi, hastaları evlerinde iki haftada bir kez olmak üzere üç ayda toplam altı kez ziyaret etmiş. Hastalara şizofreni hakkında bilgilendirme, psikotrop ilaç tedavisi, iletişim ve aile ilişkileri, sosyal beceri eğitimi, problem çözme ve krize müdahale konularında eğitim verilmiş. Sonrasında hastaların daha rahat, topluma uyum yönünden daha sorunsuz oldukları, aile içi sorunlarının azaldığı, iletişimlerinin arttığı, hoşgörülerinin ve ilaca uyumlarının arttı̆̆ı saptanmış (10).

Öncelikle ilaç tedavisinin düzenli sürdürülmesi ve terapiler tedaviye uyumun arttırılması, hastalıkla başa çıkmayı öğrenebilmesi, iletişim ve sorun çözme becerilerinin arttırılması hastanın hayat kalitesini artırmaktadır. Aynı zamanda TRSM lerde verilen hastalık ve kullandıkları ilaçlar konusundaki eğitimle, hem kendi sorumluluklarını almayı öğrenmekte, hem de bu konudaki yaşantılarını, yanlış fikirlerini ve sorunlarını paylaşabilmektedirler.

Grup eğitimi alan hastalarda toplumsal uyumun ve işlevselliğin, bağımsız yaşama becerilerinin arttı̆̆ı, daha az bireysel sıkıntı yaşadıkları, yeniden hastaneye yatışlarda daha kısa süreli yatışlara ihtiyaç duyulduğu iki yıllık izlem çalışmalarında gösterilmiştir (11)

Günümüzde TRSM lerin açılmasıyla hastalara düzenli olarak grup terapisi, uğraş terapisi, bireysel görüşmeler uygulanmaktadır. Hastalık, ilaç tedavileri ve alevlenme belirtileri konuşularak hastaların psikotik belirtilerle baş etmeyi öğrenmesi ve hastalık hakkında içgörü kazanmaları hedeflenir. Gerçeği değerlendirme yeteneğinin oluşturulması, gerçeklik duygusu gibi ego işlevlerinin güçlendirilmesi hedeflenir. Bir taraftan da hastalarımızın grup terapisi içinde aktif katılımları, katılımcıların geri bildirimleri ve diğer hastalarla etkileşimleri ile yalnızlık, dışlanmışlık duyguları azaltılarak kişiler arası ilişkileri ve iletişim becerilerinin güçlendirilmesine çalışılır. Diğer taraftan grup ortamı ile hastanın içinde yaşadığı toplumun ve yaşadığı zorlukların küçük bir modeli sağlanır. Böylece de sosyal çevrede yaşadıkları güçlükler ortaya koyularak hastanın yaşadığı güçlükler konusunda farkındalık kazanması ve bunları aşma olanağı bulmasına katkı sağlanır. Bugüne kadar ülkemizde ruhsal hastalara yönelik uyumlandırma çalışmaları sadece hastane içinde veya gündüz hastaneleri bünyesinde verilirken, ilk kez Bolu'da TRSM'de uyumlandırma çalışmalarına başlanmıştır (11-13). Bolu'da kurulan TRSM'de şizofreni hastalarına yönelik verilen hizmetlerin yaşam kalitesi, yeti yitimi, genel ve sosyal işlevsellik üzerine etkisi araştırılmış, çalışma bulguları ile toplum ruh sağlığı merkezinde verilen hizmetlerin yaşam kalitesi, genel ve sosyal işlevselliği belirgin olarak artırdığı; yeti yitimini ise önemli oranda azalttığı saptanmıştır (14).

ABD'de bir TRSM'de altı ay süre ile verilen antipsikotik ve ruhsal toplumsal uyumlandirma hizmetlerinin etkinliğinin araştırıldığı bir çalışmada hastalığın bulgularının azalmasında ve ruhsal toplumsal işlevsellikte belirgin düzelme görülmüştür (15). Yine ABD'de remisyondaki psikoz hastalarında ayaktan verilen 12 oturumluk sosyal bilişsel beceri eğitiminin yararlı olduğu görülmüştür (16). Meksika'da ruhsaltoplumsal beceri eğitimi verilen ve verilmeyen remisyondaki kronik şizofreni hastalarının karşılaştırıldığı bir çalışmada ruhsal toplumsal beceri eğitimi verilen grupta hastalık bulgularında, ruhsal toplumsal ve genel işlevsellikte istatistiksel olarak anlamlı düzeyde düzelme olduğu görülmüştür (17).

Yapılan çalışmalarda düzenli ilaç kullanımına karşın iki yıl içinde \%25, 5 y1l içinde ise \%40-60 oranında nüksden bahsedilmektedir (4). Bizim takibimizdeki hastalarda psikotik belirtilerin şiddetinin anlamlı düzeyde azaldığını ve hastalarımızın yatış gerektirecek düzeyde alevlenme yaşamadıklarını saptadık. Buna sürekli kontrol altında olmaları ve ilaç tedavilerini 
düzenli sürdürmelerinin yanı sıra ruhsal toplumsal uyumlandırma çalışmaları katkı sağlamış olabilir.

TRSM de tedavi gören hastaların alevlenme ve yatış oranları, klinik ve sosyodemografik özellikleriyle ilgili çalışmaların artması ve deneyimlerin paylaşılması bu merkezlerin verimliliğini artırabileceğini düşünmekteyiz.

\section{KAYNAKLAR}

1. Öztürk O, Ruh Sağlığı ve Bozuklukları. Yenilenmiş 11. bask1, Ankara, 2011: 242

2. Binbay T, Ulaş H, H Elbi, K Alptekin. Türkiye'de Psikoz Epidemiyolojisi: Yaygınlık Tahminleri ve Başvuru Oranları Üzerine Sistemak Bir Gözden Geçirme Türk Psikiyatri Dergisi. 2011; 22: 40-52

3. Yanık M. Türkiye ruh sağlığı sistemi üzerine değerlendirme ve öneriler, ruh sağlığ 1 eylem planı önerisi. Psikiyatride Derlemeler, Olgular ve Varsayımlar. 2007;(özel sayı):16-20

4. Remington GI, Adams ME (1994) Depot neuroleptics. Schizophrenia: Exploring the Spectrum of Psychosis, Edited by RJ Ancill, S Holliday, J Higenbotham, New York, Wiley, 1994

5. Aker T, Sungur MZ, Şizofrenide Bireysel Bilişsel ve Davranışçı Terapi Yöntemleri, Parem Yayınları, İstanbul, 2001: 11

6. Schooler NR. Relapse prevention and recovery in the treatment of schizophrenia. J Clin Psychiatry 2006; 67(Suppl.5): 19-23.

7. Soykan C: Institutional differences and case typicality as related to diagnosis system severity, prognosis and treatment. Master Tezi, Ortadoğu Teknik Üniversitesi, Ankara, 1989.

8. Kanas N. Group Therapy with Schizophrenia Patients, Am Journal of Psychiatry. 2006; 163; 93738.
9. Deveci A, Danacı AE, Yurtsever F, Deniz F, Yüksel EG. The Effects of psychosocial skills training on symptomatology, insight, quality of life, and suicide probability in schizophrenia. Türk Psikiyatri Derg. 2008; 19: 266-73

10. Doğan S, Doğan O, Tel H, Çoker F, Polatöz Ö, Doğan FB. Psychosocial approaches in outpatients with schizophrenia. Psychiatric Rehabil J. 2004; 27: $279-82$

11. Yıldız M. Şizofreni Hastaları için Ruhsal Toplumsal Beceri Eğitimi. Ankara: Türkiye Sosyal Psikiyatri Derneği Yayınları, 2011: 15

12. Thornicroft G, Szmukler G. Textbook of Community Psychiatry. Oxford, Oxford University Press, 2001

13. Yıldız M. Psikiyatrik rehabilitasyon yönelimli gündüz hastanesi uygulaması: Kocaeli Üniversitesi deneyimi. Anadolu Psikiyatri Derg. 2008; 9(Ek say1.1): 9-13.

14. Ensari H, Gültekin BK, Karaman D, Koç A, Beşkardeş AF Bolu Toplum Ruh Sağlığı Merkezi hizmetlerinin şizofreni hastalarındaki yaşam kalitesi, yeti yitimi, genel ve sosyal işlevsellik üzerine etkisi: Bir yıllık izleme sonuçları Anatolian Journal of Psychiatry. 2013; 14: 108-14

15. Noordsy DL, O'Keefe C. Effectiveness of combining atypical antipsychotics and psychosocial rehabilitation in a community mental health cen-ter setting. J Clin Psychiatry. 1999; 60(Suppl.19): $47-$ 51.

16. Horan WP, Kern RS, Shokat-Fadai K, Sergi MJ, WynnJK, Green MF. Social cognitive skills training in schizophrenia: an initial efficacy study of stabilized outpatients. Schizophr Res. 2009; 107: $47-54$

17. Valencia M, Rascon ML, Juarez F, Murow E. A psychosocial skills training approach in Mexican out-patients with schizophrenia. Psychol Med. 2007; 37: 1393-1402. 